\title{
PENGEMBANGAN SISTEM INFORMASI AKADEMIK (SIAK) BERBASIS WEB PADA SEKOLAH TINGGI KEGURUAN DAN ILMU PENDIDIKAN (STKIP) AGAMA HINDU SINGARAJA
}

\author{
I Gusti Lanang Putu Sumiantara'), I Made Ardwi Pradnyana ${ }^{2)}$, Ketut Agustini ${ }^{3)}$ \\ ${ }^{1}$ Fakultas Teknik dan Kejuruan, Universitas Pendidikan Ganesha \\ Email: lanangjik@gmail.com, ardwi.pradnyana@undiksha.ac.id, ketut.agustini@undiksha.ac.id
}

\begin{abstract}
Abstrak
Sekolah Tinggi Keguruan dan IImu Pendidikan (STKIP) Agama Hindu Singaraja belum mempunyai sebuah sistem informasi yang menunjang hal-hal yang berkaitan dengan akademik. Sistem Informasi akademik yang diterapkan saat ini masih bersifat manual dan memiliki beberapa kelemahan, seperti antrian siswa pada interval tertentu, sehingga akan memperlambat proses. Untuk mengatasi masalah ini, dibuat Sistem Informasi Akademik (SIAK) berbasis web untuk memfasilitasi proses belajar mengajar dan administrasi siswa agar dapat mematuhi kalender akademik yang berasal dari perguruan tinggi. Proses dan fitur yang akan terkandung dalam SIAK disesuaikan dengan permintaan STKIP agama Hindu Singaraja. Dalam pengembangannya, Sistem informasi akademik ini menggunakan model waterfall dan menggunakan framework codeigniter. Sistem ini dapat berjalan secara online sesuai dengan kebutuhan dari STKIP Agama Hindu Singaraja. Hasil dari penelitian ini berupa Sistem Informasi yang dapat diakses melalui komputer client ataupun server. Berdasarkan hasil pengujian, sistem informasi bekerja dengan baik. Sistem dinilai mampu membantu maslah administrasi denan presentasi niai yaitu $79 \%$. Sistem mendapat respon yang positif dari pengguna.
\end{abstract}

Kata kunci: Model Waterfall, framework codeigniter,sistem informasi.

\begin{abstract}
Sekolah Tinggi Keguruan dan IImu Pendidikan (STKIP) Agama Hindu Singaraja does not yet have an information system that supports some that are related to academics. The academic information system applied today is still manual and has several weaknesses, such as student queues at certain intervals, which will slow down the process. To overcome this problem, a web-based Academic Information System was created to facilitate the teaching and learning process and the administration of students to be able to comply with academic calendars from universities. The process and features that will be contained in Academic Information System are adjusted to the Hindu's Teacher Training and Education Colege Singaraja request. In its development, this academic information system uses the waterfall model and uses codeigniter framework. From this development, it was previously designed with the help of activity diagrams and use case diagrams. In its development, this academic information system uses the waterfall model and uses codeigniter framework. This system can run online according to the needs of STKIP Singaraja Hindu Religion. The results of this study are in the form of Information Systems that can be accessed through client computers or servers. Based on the results of testing, the information system works well. The system is considered able to help deal with administrative presentations, namely $79 \%$. The system received a positive response from users.
\end{abstract}

Keywords : waterfall method, framework codeigniter, Information System. 


\section{PENDAHULUAN}

Saat ini, kita telah berada dalam sebuah era yang sarat dengan teknologi komunikasi dan informasi. Kemajauan teknologi telah memberikan sumber (resources) informasi dan komunikasi yang amat luas dari apa yang telah dimiliki manusia. Meskipun peranan informasi dalam beberapa dekade kurang mendapat perhatian, namun sesungguhnya kebutuhan akan informasi dan komunikasi itu merupakan hal yang tidak kalah pentingnya dari kebutuhan sandang dan pangan manusia.

Seperti yang kita lihat dewasa ini, banyak sekali perubahan yang terjadi di bidang komunikasi. Dimulai dari bentuk komunikasi yang sederhana sampai pada komunikasi elektronik. Perubahan yang cepat terutama pada abad 20 ini oleh sejumlah ahli dikatakan sebagai revolusi komunikasi. IImu pengetahuan yang selama ini kita pelajari selalu mengalami perubahan dan perkembangan yang tidak mendadak. Perubahan ini ada yang terjadi secara perlahan, ada pula yang terjadi secara drastis akibat pertentangan antara satu ilmu pengetahuan dengan ilmu pengetahuan yang baru, atau pertentangan antara teori yang lama yang digantikan dengan penemuan teori baru dalam pengetahuan [1]. Seiring dengan perkembangan pola pikir manusia dari masa ke masa, perkembangan teknologi semakin pesat. Perangkat penyedia informasi dalam memenuhi kebutuhan manusia pun hadir dengan berbagai model. Sehingga sangat dibutuhkan sebuah perangkat yang dapat mengolah dan mengelola informasi dengan cepat, tepat dan up to date. Perangkat ini didasarkan pada kerja sistem berdasarkan prosedurnya dalam menyelesaikan suatu sasaran tertentu. Sistem tersebut dibangun dan atau dirancang guna menjawab kebutuhan manusia dalam organisasi tertentu akan penyediaan informasi yang tepat guna. Hal ini juga yang menjadi faktor pendorong bagi berbagai lembaga maupun organisasi untuk memiliki sebuah sistem informasi sebagai sarana untuk menyampaikan informasi secara global.

Pengembangan sistem informasi dalam bidang akademik sudah banyak dikembangkan yaitu penelitian yang mengembangkan sebuah sistem, sistem tersebut menyediakan informasi kegiatan laporan aktivitas online dalam bentuk laporan siswa kelas, laporan kehadiran, laporan kuliah, dan informasi lain yang terkait dengan bidang akademik [2]. Sistem Informasi Akademik berbasis WEB, sehingga membantu kecepatan dan kualitas dalam penyampaian informasi. Pengembangan teknologi akademik juga sudah banyak dikembangkan yaitu Penelitian yang menghasilkan aplikasi, aplikasi ini memiliki fitur cuti akademik, non aktif akademik, ujian bentrok, ujian susulan, pindah kelas, pindah jurusan dan pengecekan nilai. Dengan demikian dapat mengurangi waktu tunggu mahasiswa dalam penyelesaian pelayanan akademik dan mengurangi panjangnya antrean pelayanan [3].

Kebutuhan akan informasi tentunya memudahkan Suatu organisasi untuk memanajemen organisasi tersebut dalam bidang teknologi informasi salah satu organisasi digunakan oleh perguruan tinggi. Ketika peneliti melakukan suatu observasi dan wawancara di salah satu Perguruan tinggi yaitu Sekolah Tinggi Keguruan dan IImu Pendidikan Agama Hindu yang berada di singaraja, peneliti menemukan permasalahan mengenai kebutuhan informasi akademik. Berdasarkan wawancara dan observasi di temukan permasalahan bahwa sistem akademik STKIP Agama Hindu Singaraja dikelola oleh KA. BAAK. Sistem akademik yang digunakan KA. BAAK masih berbasis desktop. Mahasiswa yang berkepentingan untuk mengurus administrasi akademik harus datang langsung ke KA.BAAK. Penerapan ini yang dirasa kurang efisien dilakukan. Hal ini didukung oleh pernyataan beberapa mahasiswa dari pengisian angket yang disebarkan. Sebagian besar mahasiswa mengeluhkan prihal antrian mahasiswa dalam selang waktu yang lama untuk penyusunan Kartu Rencana Studi (KRS) [4].

Dari permasalahan yang ada, peneliti menemukan sebuah solusi untuk mengatasi hal tersebut yaitu mengembangan sebuah sistem informasi akademik Berbasis Web, sehingga peneliti termotivasi untuk membuat penelitian yang berjudul "Pengembangan Sistem Informasi Akademik (SIAK) Berbasis Web Pada Sekolah Tinggi Keguruan dan IImu Pendidikan (STKIP) Agama Hindu Singaraja".

Dengan adanya pengembangan SIAK ini, diharapkan dapat membantu pihak Perguruan tinggi dalam proses administrasi akademis khususnya pada pengelolaan KRS dan cuti online bagi para mahasiswa. Selain itu system juga dapat mengelola data dosen, data pegawai, data jabatan, golongan hingga data mata kulliah. 


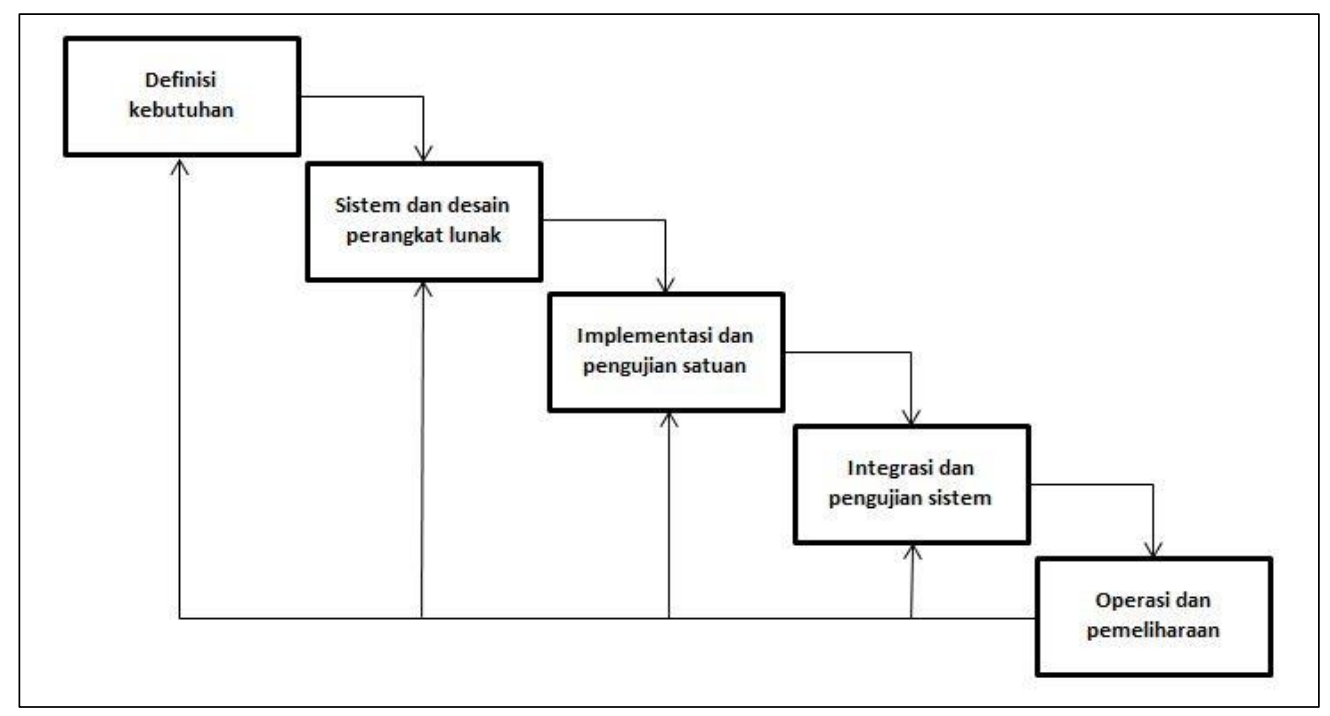

Gambar 1. Tahapan Model Waterfall Sistem Informasi Akademik

Berdasarkan dari pemikiran ini penulis memandang permasalahan dapat diatasi dengan mengembangkan: Pengembangan Sistem Informasi Akademik (SIAK) Berbasis Web pada Sekolah Tinggi Keguruan dan IImu Pendidikan Agama Hindu Singaraja.

\section{METODE}

Pengembangan Sistem Informasi Akademik menggunakan metode System Development Life Cycle (SDLC) yaitu dengan model penelitian waterfall. Model waterfall atau air terjun, yang kadang dinamakan siklus hidup klasik adalah pendekatan pengembangan perangkat lunak yang sistematis dan berurutan (sequential linier), yang dimulai dengan spesifikasi kebutuhan pengguna yang di tunjukan pada gambar 1 [5].

Model penelitian Waterfall memiliki fase - fase atau tahapan/prosedur dari model waterfall sebagai berikut, tahapan yang pertama adalah Analisa Kebutuhan (Requirements analysis and definition), Desain Sistem (System and software design), Implementasi (Implementation and unit testing), Integrasi dan Pengujian(Integration and system testing), Pemeliharaan (Operation and maintenance) pengujian yang diakhiri dengan dukungan berkelanjutan pada perangkat lunak lengkap yang dihasilkan [6]

A. Analisis Masalah yaitu Berdasarkan observasi, angket, dan wawancara di temukan permasalahan bahwa sistem akademik STKIP agama hindu singaraja dikelola oleh KA.BAAK. Sistem akademik yang digunakan KA.BAAK masih berbasis desktop. Mahasiswa yang berkepentingan untuk mengurus administrasi akademik harus datang langsung ke KA.BAAK. Penerapan ini yang dirasa kurang efisien dilakukan. Hal ini didukung oleh pernyataan beberapa mahasiswa dari pengisian angket yang disebarkan. Sebagian besar mahasiswa mengeluhkan prihal antrian mahasiswa dalam selang waktu yang lama untuk penyusunan KRS. maka solusi yang dapat diusulkan adalah pengembangan perangkat lunak Sistem Informasi Akademik (SIAK) Berbasis Web Pada Sekolah Tinggi Keguruan dan IImu Pendidikan (STKIP) Agama Hindu Singaraja Perangkat lunak ini diharapkan mampu menangani permasalahan yang menjadi kelemahan di atas dan membantu efektifitas kinerja didalam Lembaga pendidikan [1]. Kemudian dilanjutkan dengan

B. Analisis Perangkat Lunak yang dibagi menjadi : (1) Kebutuhan Perangkat lunak. Berdasarkan analisis terhadap pengembangan sistem, adapun beberapa kebutuhan yang dirancang dalam mengembangkan Sistem Informasi Akademik (SIAK) Berbasis Web Pada Sekolah Tinggi Keguruan dan IImu Pendidikan (STKIP) Agama Hindu Singaraja antara lain, Sistem dapat Mengelola Data Dosen, Sistem dapat Mengelola Data Pegawai, Sistem dapat mengelola data mahasiswa, Sistem dapat Mengelola Data Jenis Matakuliah, Sistem dapat Mengelola Data Mata Kuliah, Sistem dapat Mengelola Data Prodi, Sistem dapat mengelola Data Golongan, Sistem dapat mengelola Data Jabatan, Sistem dapat mengelola Data Tahun Ajar, Sistem dapat mengelola Data Kelas, Sistem dapat mengelola Data Agama,.Kebutuhan nonfungsional perangkat lunak antara lain, perangkat lunak ini memiliki antarmuka bersifat friendly mudah digunakan dan mudah diperasikan.

Sistem dilengkapi dengan hak akses pengguna yang dibagi menjadi admin, pegawai,dosen, dan mahasiswa. Sistem dirancang untuk dapat digunakan online agar dapat memberikan informasi secara realtime. (2) Tujuan perangkat lunak. Adapun tujuan penelitian ini adalah membantu Lembaga Sekolah Tinggi Keguruan dan IImu Pendidikan (STKIP) Agama Hindu Singaraja dalam melakukan administrasi agar lebih efektif dan efisien. Secara rinci tujuan yang ingin dicapai adalah sebagai 
berikut : (a) Membantu pengguna mengelola informasi terkait Lembaga Pendidikan, (b) Membantu mengelola data informasi dosen, (c) Membantu mengelola data informasi pegawai, (d) Membantu pengguna mengelola data informasi mahasiswa. (3) Masukan dan keluaran. Masukan pada perangkat lunak Sistem Informasi Akademik yaitu : Data Login, Data Mahasiswa, Data jadwal perkuliahan, Data Nilai Mahasiswa, Data Perkembangan Mahasiswa, Data Dosen, Data Pegawai, Data KRS, Data Kartu Hasil Studi (KHS), Data Transkrip Nilai, Data Cuti, Data wisuda, Data Matakuliah. Keluarannya yaitu Hak akses, Informasi Data Mahasiswa, Informasi Data KRS, Informasi Nilai Mahasiswa, Informasi Perkembangan Mahasiswa, Informasi Data Dosen, Informasi Data KHS, Informasi Jadwal perkuliahan. (4) Model fungsional perangkat lunak digunakan untuk menjelaskan bagaimana gambaran umum dari perangkat lunak yang akan dikembangkan [7]. Gambaran umum yang dibuat divisualisasikan dalam bentuk gambar ataupun diagram agar dapat dimengerti oleh pihak lain. Salah satu design sistem yang digunakan oleh berbagai kalangan adalah UML (Unified Modelling Language).

Tabel 1. Deskripsi Aktor Sistem Informasi Akademik STKIP AH Singaraja

\begin{tabular}{|c|c|c|}
\hline No. & Nama Aktor & Deskripsi \\
\hline 1 & Admin & $\begin{array}{l}\text { Admin merupakan user yang memiliki hak akses untuk dapat } \\
\text { mengakases secara penuh kebutuhan perangkat lunak }\end{array}$ \\
\hline 2 & Pegawai & $\begin{array}{l}\text { Pegawai merupakan user yang dapat menangani } \\
\text { secara penuh semua keperluan terkait administrasi } \\
\text { pendidikan mahasiswa }\end{array}$ \\
\hline 3 & Dosen & $\begin{array}{l}\text { Dosen merupakan user yang menangani proses belajar } \\
\text { mengajar dan begitu juga input nilai }\end{array}$ \\
\hline 4 & Mahasiswa & $\begin{array}{l}\text { Mahasiswa merupakan user pengguna sistem untuk melakukan } \\
\text { Registrasi di sistem setiap } 6 \text { bulan nya }\end{array}$ \\
\hline
\end{tabular}

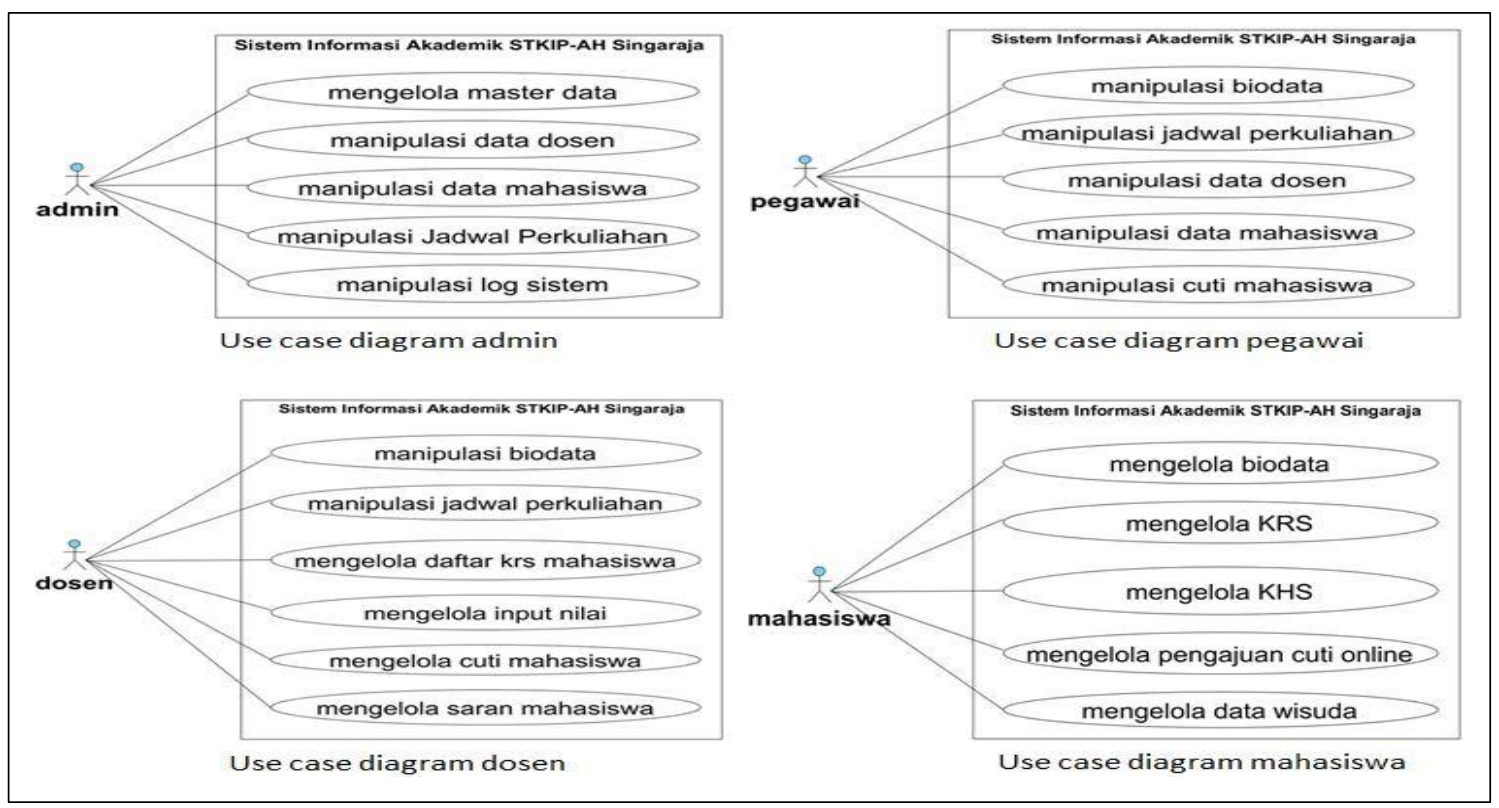

Gambar 2. Use Case Diagram Sistem Informasi Akademik STKIP-AH

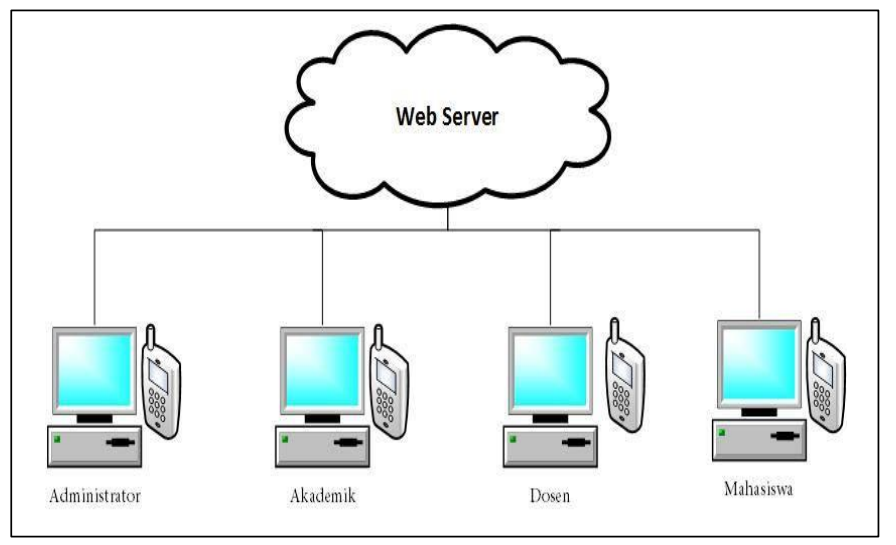

Gambar 3. Arsitektur Komputer Sistem Informasi Akademik STKIP-AH 
UML merupakan Bahasa standar industri yang digunakan untuk merancang, dan mendokumentasikan perangkat lunak yang akan dikembangkan. Gambar 2 menunjukan Use Case Diagram dari perangkat lunak. Definisi aktor merupakan penjelasan dari apa yang dilakukan oleh aktor-aktor yang terlibat dalam perangkat lunak yang dirancang. Adapun deskripsi dari aktor-aktor yang terlibat dalam Perangkat Lunak Sistem Informasi akademik STKIP-AH dipaparkan pada Tabel 1.

C. Perancangan Perangkat Lunak Sistem Informasi Akademik Sekolah Tinggi Keguruan dan IImu Pendidikan Agama Hindu Singaraja dirancang menggunakan 24 tabel basis data yang berfungsi menyimpan data sesuai dengan peruntukannya pada proses-proses tertentu. Selain perancangan table juga dirancang hubungan basis data yaitu dengan. Entity Relationship Diagram (ERD) merupakan suatu cara untuk menjelaskan kepada para pemakai tentang hubungan antar data dalam basis data secara logic dengan persepsi bahwa real world terdiri dari objek-objek dasar yang saling berhubungan dengan cara menvisualisasikan ke dalam bentuk simbol-simbol grafis [8]. Arsitektur perangkat lunak Sistem. Sistem Informasi Akademik Sekolah Tinggi Keguruan dan Ilmu Pendidikan Agama Hindu Singaraja menggunakan arsitektur client server yang mana arsitektur client server merupakan arsitektur yang sudah banyak digunakan dalam berbagai pengembangan sistem informasi. Pada arsitektur ini server akan memberikan informasi kepada client sesuai dengan kebutuhan yang dilakukan pada client. Adapun gambar Arsitektur Komputer dijelaskan pada gambar 3 di atas. Pada bagain server menggunakan Codelgniter (Cl) sebagai framework untuk mengembangkan sistem. Codelgniter sangat menarik, sehingga apapun yang ditulis dalam Codelgniter dapat dikemas dalam sebuah kemasan yang simpel [9].

\section{HASIL DAN PEMBAHASAN}

Berdasarkan implementasi dari hasil analisis dan perancangan perangkat lunak Sistem Informasi Akademik (SIAK) Sekolah Tinggi Keguruan dan IImu Pendidikan (STKIP) Agama Hindu Singaraja terdapat beberapa hasil implementasi yaitu

A. Implementasi Perangkat Lunak, pada implementasi perangkat lunak dibagi menjadi dua yaitu : (1) Lingkungan Implementasi Perangkat Lunak dalam lingkungan perangkat lunak dibahas : (a) Spesifikasi Perangkat Keras Sistem Informasi Akademik Sekolah Tinggi Keguruan dan IImu Pendidikan Agama Hindu Singaraja ini dikembangkan pada lingkungan perangkat keras komputer mobile (laptop) yang memiliki spesifikasi sebagai berikut : (1) Processor Intel core i5 2.20GHz, (2) RAM 4 GB, (3) Kartu Grafis Nvidia GeForce 720M 2 GB, (4) Monitor 14 inch dengan resolusi 1366 × 786 px. kemudian pada (b) Spesifikasi Sistem Informasi Akademik Sekolah Tinggi Keguruan dan IImu Pendidikan Agama Hindu Singaraja dikembangkan pada lingkungan perangkat lunak sebagai berikut : (1) Sistem Operasi Microsoft Windows 8.1 Pro 64-bit, (2) Bahasa pemrograman Java, Codelgniter (CI), XML, PHP, HTML5, CSS3, JavaScript dan MySQL, (3) Database server package yang digunakan adalah XAMPP versi 3.3.2, (4) Google Chrome browser, (5) Web framework Codelgniter (6) Text editor Sublime Text, (2) Implementasi Antarmuka Perangkat Lunak dapat di lihat Pada gambar dibawah :

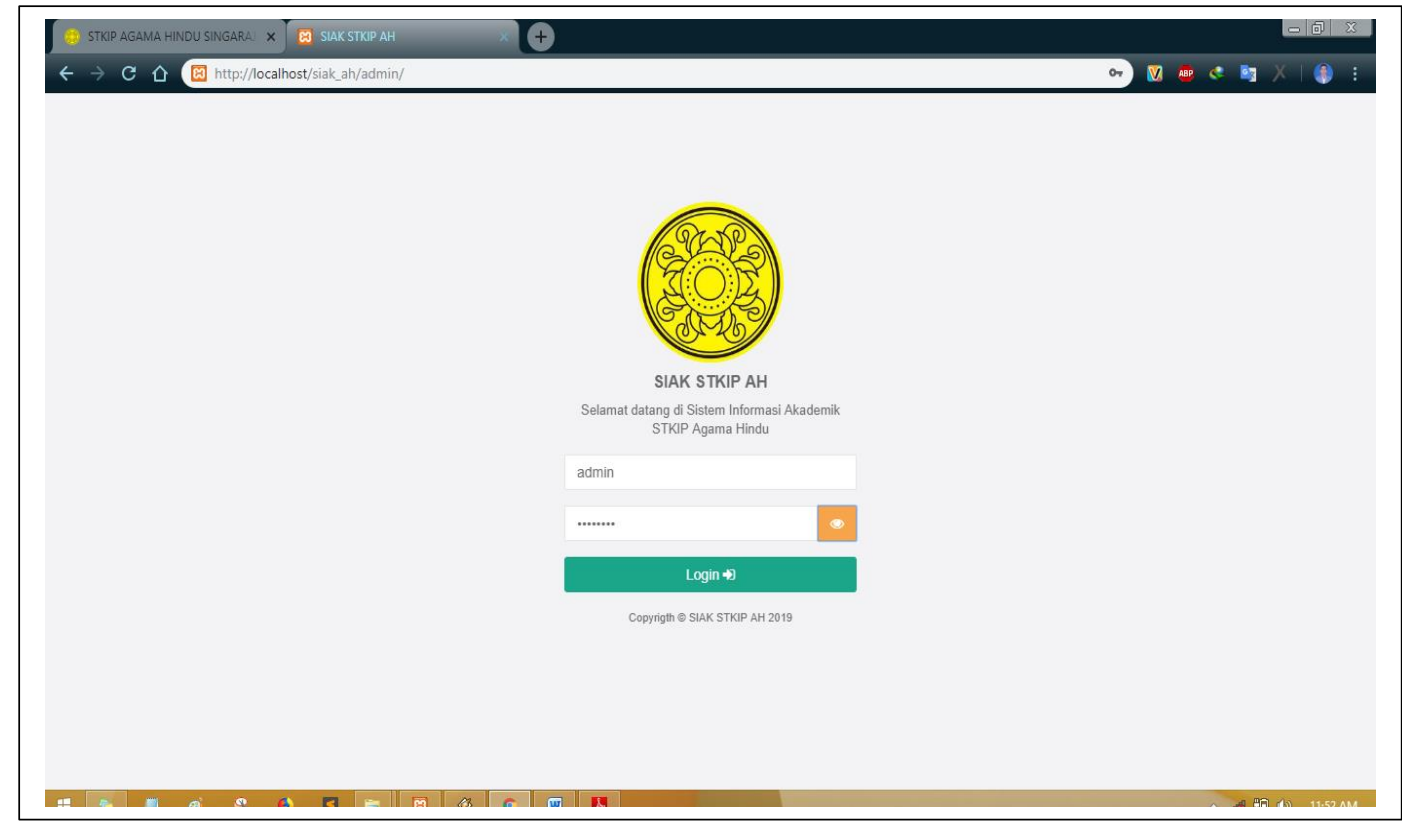

Gambar 4. Halaman Login Sistem Informasi Akademik STKIP-AH 
gambar 4 merupakan tampilan antarmuka Login untuk masuk ke sistem setiap user yang merupakan halaman yang ditampil saat pertama kali user mengakses sistem informasi akademik STKIP-AH.

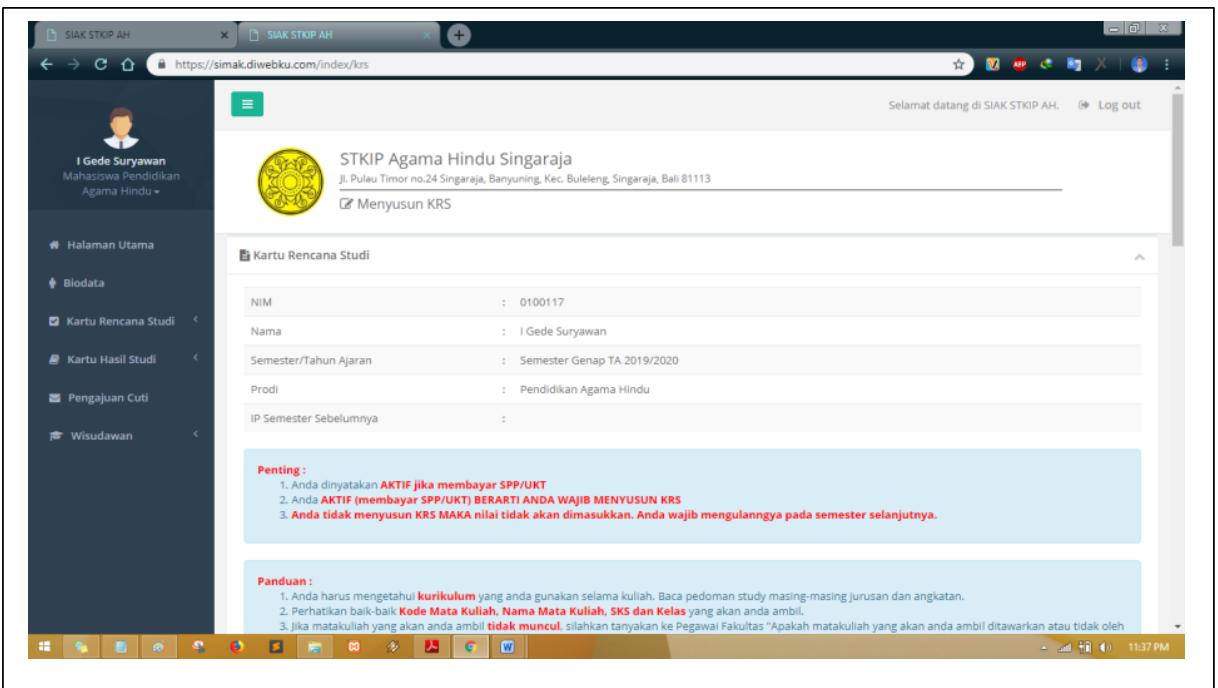

Gambar 5. Tampilan Halaman penyusunan KRS Mahasiswa

gambar 5 merupakan halaman untuk mahasiswa melakukan rencana studi atau dengan kata lain penyusunan Kartu Rencana Studi (KRS) selama satu semester sekali

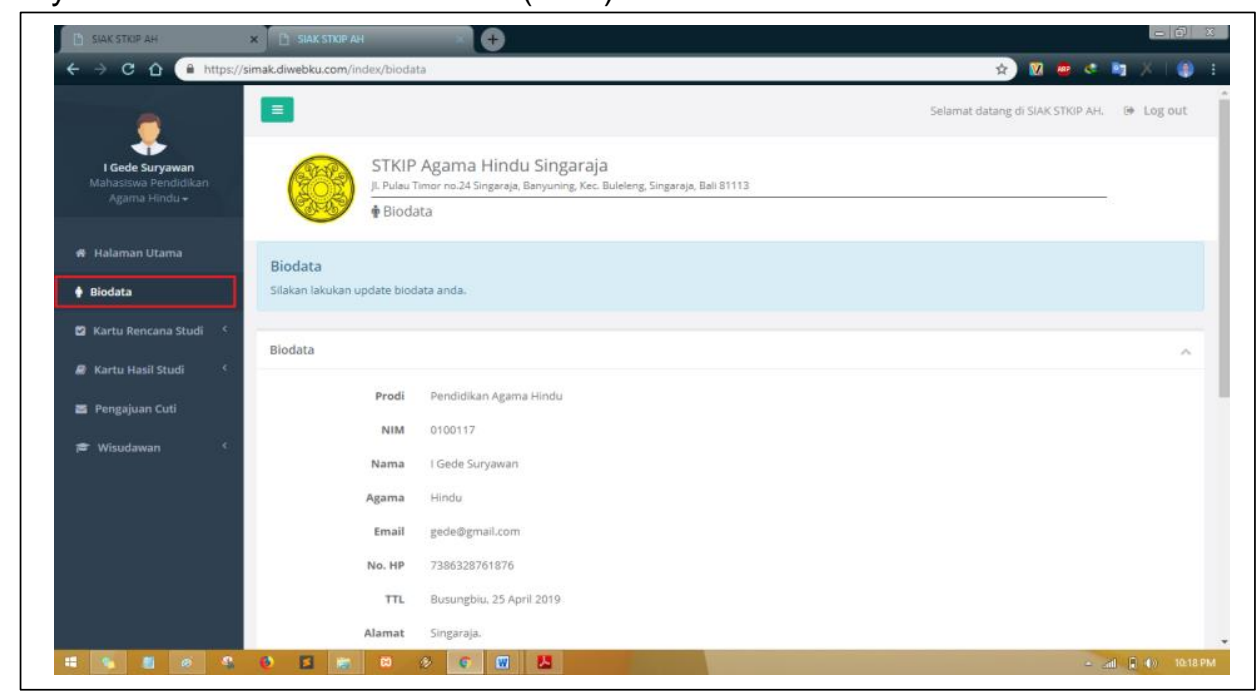

Gambar 6. Tampilan Halaman Biodata Mahasiswa

Gambar 6 menunjukan halaman dashboard untuk mahasiswa melakukan manipulasi biodatanya sendiri

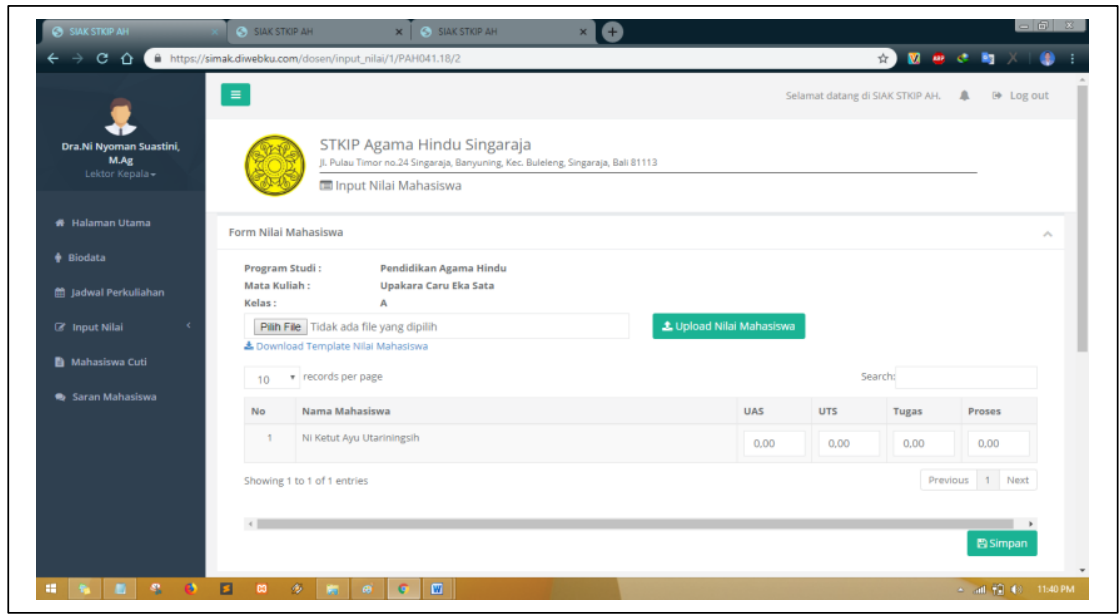

Gambar 7. Tampilan Halaman Input nilai oleh dosen 

semester.

gambar 7 yaitu halaman dashboard untuk dosen manipulasi nilai mahasiswa setiap satu

B. Pengujian Perangkat Lunak, dalam pengujian perangkat lunak dibagi menjadi empat tahapan yang pertama adalah : (a) Tujuan pegujian perangkat lunak dalam tujuan perangkat lunak (1) Whitebox testing, dilakukan dengan memeriksa logika kode program yang telah dibuat dengan menguji beberapa modul dengan hasil output yang dihasilkan. (2), Blackbox testing juga disebut functional testing, sebuah teknik pengujian fungsional yang merancang test case berdasarkan informasi dari spesifikasi.(3) Pengujian dengan Metode SUS, dilakukan untuk menguji respon pengguna terhadap sistem [10], dalam hal ini Admin, sebagai pengguna sistem informasi. (4) Pengujian Kelayakan, bertujuan untuk mengetahui apakah sistem layak untuk di implementasikan. Kemudian dilanjutkan dengan (b) Tata ancang dan teknik pengujian perangkat lunak yaitu : (1) Whitebox testing, meliputi pengujian kesesuaian implementasi proses dan algoritma yang dibutuhkan untuk berbagai proses membuat, mengubah, dan menghapus data masukan dari pengguna. (2) Blackbox testing, meliputi pengujian seluruh fungsi dan kesesuain inputan, proses dan keluaran yang dihasilkan sistem yang telah dijalanan oleh pengguna, sehingga dapat dipantau keberhasilan proses tersebut. (3) Pengujian Lapangan, pengujian ini dilakukan untuk menguji respon pengguna terhadap sistem yang telah berjalan. (4) Pengujian Kelayakan, meliputi pengujian kebenaran fungsifungsi yang telah berjalan pada sistem sebagai pendukung dalam pembuatan keputusan dalam penentuan prioritas perbaikan jalan. Tahap yang ketiga adalah (c) Pelaksanaa pengujian perangkat lunak ,adapun pelaksanaan pegujian perangkat lunak sebagai berikut : (1) Pengujian kotak putih dilaksanakan pada 29 mei 2019 dilakukan oleh peneliti. pengujian yang dilakukan sesuai tata ancang yang sudah dipersiapkan. (2) Pengujia kotak hitam dilaksanakan pada tanggal 3 mei 2018 oleh dua orang penguji, yaitu 1). irfan, 2). Gede Sukadana. Pada tanggal 6 mei 2019 oleh satu orang penguji yaitu Kepala BAAK yang mengurus administrasi semua mahasiswa dari menyusun/pemilihan matakuliah dan persiapan ujian. (3) Pengujian respon pengguna menggunakan metode System usability testing (SUS) yang dilakukan pada tanggal 10 mei 2019 oleh Mahasiswa,dosen,dan pegawai yang berada dilingkungan STKIP-AH.

Tabel 3. Hasil Respon Pengguna Sistem Informasi Akademik STKIP-AH

\begin{tabular}{ccccccccccccc} 
Responden & \multicolumn{10}{c}{ Jawaban Responden untuk Item Nomor } & Skor Total $\begin{array}{c}\text { Rata-rata } \\
(\%)\end{array}$ \\
\hline & $\mathbf{1}$ & $\mathbf{2}$ & $\mathbf{3}$ & $\mathbf{4}$ & $\mathbf{5}$ & $\mathbf{6}$ & $\mathbf{7}$ & $\mathbf{8}$ & $\mathbf{9}$ & $\mathbf{1 0}$ & & \\
\hline R1 & 3 & 4 & 4 & 2 & 4 & 4 & 3 & 1 & 2 & 4 & 31 & 77.5 \\
R2 & 3 & 3 & 4 & 3 & 3 & 4 & 4 & 4 & 4 & 2 & 34 & 85 \\
R3 & 4 & 3 & 4 & 4 & 4 & 3 & 2 & 4 & 3 & 2 & 33 & 82.5 \\
R4 & 3 & 3 & 4 & 4 & 3 & 4 & 3 & 4 & 3 & 2 & 33 & 82.5 \\
R5 & 3 & 2 & 3 & 3 & 3 & 3 & 4 & 3 & 3 & 0 & 27 & 67.5
\end{tabular}

Berdasarkan persentase keseluruhan subyek maka diperoleh hasil respon adalah Baik, yaitu 79 \%. (4) Pengujian ini dilaksanakan pada tanggal 10 Mei 2019 oleh Mahasiswa,dosen, dan Pegawai di STKIP-AH. Adapun hasil pengujian yang telah dilaksanakan bahwa data yang diinputkan oleh user sesuai dengan data yang ditampilkan oleh sistem. Maka sistem informasi Akademik LAYAK digunakan di Sekolah Tinggi Keguruan dan IImu Pendidikan(STKIP) Agama Hindu Singaraja.

Tahap yang terakhir adalah (d) Evaluasi hasil pengujian perangkat lunak, Pelaksanaan pengujian perangkat lunak berlangsung dengan baik dan lancar. Berdasarkan hasil pengujian whitebox testing (pengujian struktural) diperoleh bahwa implementasi algortima telah berhasil sehingga mendapatkan hasil yang sesuai. Kemudian pengujian blackbox testing (pengujian fungsionalitas) diperoleh bahwa semua proses yang dilakukan oleh user mampu berjalan dengan baik dan menghasilkan inputan yang sesuai dengan spesifikasi. Selanjutnya berdasarkan pengujian respon pengguna atau pengujian lapangan diproleh hasil baik atau sebesar $79 \%$ yang mana menyatakan bahwa sistem telah memenuhi kebutuhan dari user. Pada pengujian kelayakan sistem hasil yang diperoleh bahwa SIstem Informasi Akademik (SIAK) Berbasis Web.

Pada Sekolah Tinggi Keguruan dan IImu Pendidikan(STKIP) Agama Hindu LAYAK diterapkan sebagai sistem administrasi untuk menunjang efektfitas dan efisiensi akademik di STKIP-AH. Sistem Informasi Akademik (SIAK) Berbasis Web Pada Sekolah Tinggi Keguruan dan IImu Pendidikan (STKIP) Agama Hindu Singaraja dalam pembuatannya menerapakan metode System Development Life Cycle (SDLC) dengan model waterfall. Ada pun tahapan penelitian dari metode tersebut adalah 
Analisa Kebutuhan (Requirements analysis and definition), Desain Sistem (System and software design), Implementasi (Implementation and unit testing), Integrasi dan Pengujian (Integration and system testing) [11].

Pada tahap Analisa Kebutuhan (Requirements analysis and definition) peneliti melakukan pencarian informasi dengan observasi, wawancara dan angket/kuisioner di lingkungan Sekolah Tinggi Keguruan dan IImu Pendidikan (STKIP) Agama Hindu Singaraja. Berdasarkan wawancara dan observasi di temukan permasalahan bahwa sistem akademik STKIP agama hindu Singaraja dikelola oleh KA.BAAK. Sistem akademik yang digunakan KA.BAAK berbasis desktop. Mahasiswa yang berkepentingan untuk mengurus administrasi akademik harus datang langsung ke KA.BAAK. Penerapan ini yang dirasa kurang efisien dilakukan. Hal ini didukung oleh pernyataan beberapa mahasiswa dari pengisian angket yang disebarkan. Sebagian besar mahasiswa mengeluhkan prihal antrian mahasiswa dalam selang waktu yang lama untuk penyusunan KRS.

Selanjutnya adalah tahap perancangan (System dan Software Design) tahap perancangan perangkat lunak dibuat berdasarkan pada tahap analisis yang telah dilakukan sebelumnya. Hasil rancangan perangkat lunak yang dibuat akan menjadi dasar dalam melakukan implementasi perangkat lunak [12].

Sistem Informasi Akademik (SIAK) Berbasis Web Pada Sekolah Tinggi Keguruan dan IImu Pendidikan (STKIP) Agama Hindu Singaraja pada tahap implementasi dikembangkan dengan menggunakan Web Framework Codelgniter $(\mathrm{Cl})$. Pengembangan sistem informasi ini menggunakan arsitektur komputer client-server, web base pada sisi server pada sisi client. Pada web base beberapa fungsi yang diimplementasikan adalah fungsi pengelolaan data seperti. Membantu pengguna mengelola informasi terkait lembaga pendidikan, membantu pengguna mengelola data informasi dosen, mengelola data informasi pegawai, dan mengelola data informasi mahasiswa

Sistem Informasi Akademik (SIAK) Berbasis Web Pada Sekolah Tinggi Keguruan dan IImu Pendidikan (STKIP) Agama Hindu Singaraja telah berhasil dikembangkan dan telah berhasil di melalui tahap pengujian. Pengujian respon pengguna menggunakan metode System Usability Scale (SUS) menunjukan nilai sebesar $79 \%$ yang menyatakan bahwa semua kebutuhan dari pengguna telah terpenuhi. Pada pengujian kelayakan sistem informasi terpadu dinyatakan layak karena semua data yang diinputkan oleh user sesuai dengan yang dihasilkan oleh sistem. Berdasarkan hasil dari beberapa pengujian yang dilakukan dapat dinyatakan bahwa tujuan penelitian sudah tercapai. Hal tersebut dilihat dari hasil pengujian struktural (whitebox testing), pengujian fungsional (blackbox testing), pengujian lapangan (respon pengguna), pengujian kelayakan sistem yang mendapatkan hasil yang baik [13].

\section{SIMPULAN DAN SARAN}

Berdasarkan paparan hasil analisis, perancangan, implementasi, dan pengujian Sistem Informasi Akademik (SIAK) Berbasis Web Pada Sekolah Tinggi Keguruan dan IImu Pendidikan (STKIP) Agama Hindu Singaraja yang telah dilaksanakan pada penelitian ini maka dapat diambil kesimpulan sebagai berikut Pengembangan Sistem Informasi Terpadu berhasil mengatasi masalah yang terjadi pada Lembaga Sekolah Tinggi Keguruan dan IImu Pendidikan Agama Hindu Singaraja. Dikembangkan dengan Metode SDLC dengan model Waterfall pengembangan dari sistem ini berjalan sesuai rule model yang digunakan yang mana setiap tahapannya dilakukan evaluasi untuk mendapatkan hasil yang maksimal. Sistem Informasi Akademik dengan dasar menggunakan web sebagai plaform utama yang memudahkan pengguna untuk mengakses sistem ini. Platform web dalam permasalahan administratif sangat membantu untuk meningkatkan efisiensi waktu dalam segala pekerjaan. Berdasarkan hasil pengujian, sistem informasi bekerja dengan baik. Sistem dinilai mampu membantu maslah administrasi denan presentasi niai yaitu $79 \%$. Sistem mendapat respon yang positif dari pengguna.

Berdasarkan hasil penelitian yang sudah dipaparkan sebelumnya, terdapat beberapa saran untuk peneliti yang melakukan penelitian selanjutnya yaitu sebagai berikut :

1) Sistem informasi yang dikembangkan agar ditambahkan fitur chat real time untuk membantu komunikasi lebih baik yaitu komunikasi dua arah antara kampus dan orang tua.

2) Proses login user dapat ditambahkan fitur menggunakan media sosial seperti facebook, twitter, atau yang lainnya

3) Penelitian selanjutnya dapat dilakukan dengan pengujian usability testing terhadap sistem informasi akademik berbasis web pada Sekolah Tinggi Keguruan dan IImu Pendidikan (STKIP) Agama Hindu Singaraja. 


\section{DAFTAR PUSTAKA}

[1] A, Ahmad. (2012)."Perkembangan Teknologi Komunikasi dan Informasi : Akar Revolusi dan Berbagai Standarnya," Jurnal Dakwah Tabligh, pp. 137-149,.

[2] Sudarmaji. (2012). "Perancangan Sistem Informasi Akademik Berbasis Web Pada Program Diploma III Manajemen Informatika UM Metro Lampung," Jurnal Informatika, vol. 12, no. 2, pp. 198-207.

[3] Jogiyanto. (2005). Analisis \& Desain. Yogyakarta: ANDI, pp. 1-14.

[4] M. Dosen, "Perbedaan Kebutuhan Fungsional dan Non Fungsional, Lengkap Contoh dan Penjelasan," 22 maret 2017. [Online]. Available: http://www.materidosen.com/2017/03/perbedaankebutuhan-fungsional-dan-non.html. [Accessed 4 juni 2019].

[5] rose, AS, Shalahudin, m. (2011). Modul Pembelajaran, Rekayasa Perangkat Lunak (Terstruktur Dan Berorientasi Objek), Bandung: MODULA,.

[6] I, Sommerville. ( 2011). SOFTWARE ENGINEERING, United States of America: AddisonWesley,.

[7] Betha, Pohan, Iskandar husni. (2002). Sidik, HTML dan XML, Bandung: Informatika,.

[8] Yulherniwati, A, Ikhsan. (2013). "Perancangan Basis Data untuk Pengembangan Sistem Informasi Akademik Berbasis Web Jurusan Teknologi Informasi Politeknik Negeri Padang," Jurnal Teknik Industri, pp. 13-25.

[9] T. Haryanto, "CODEPOLITAN Codelgniter Framework," 12 oktober 2014. [Online]. Available: https://www.codepolitan.com/codeigniter-php-framework-sekarang-punya-rumah-baru. [Accessed 4 Juni 2019].

[10] Usman Panjaitan, Febriyanti, Ependi. (2018). "System Usability Scale Antarmuka Palembang Guide Sebagai Media Pendukung Asian Games XVIII," Journal of Information Systems Engineering and Business Intelligence, pp. 101-107,.

[11] Hidayatullah, Kawistara, Khairul, Jauhari, Priyanto. (2014). PEMROGRAMAN WEB, Bandung: Informatika.

[12] Saliman. (2017). "Sistem Informasi Berbasis Komputer (CBIS)," Sistem Informasi Berbasis Komputer (CBIS), pp. 45-58.

[13] rizki, aditya, Saputra, Sulistiowati,Julianto, Lemantara. (2016). "Rancang Bangun Sistem Informasi Akademik Mahasiswa Berbasis Web pada "Akbid Griya Husada" Surabaya," JSIKA, pp. $1-8$. 